\title{
Experimental Stage Separation Tool Development in NASA Langley's Aerothermodynamics Laboratory
}

\author{
Kelly J. Murphy*, William I. Scallion ${ }^{\dagger}$ \\ NASA Langley Research Center \\ Hampton, VA 23681
}

\begin{abstract}
As part of the research effort at NASA in support of the stage separation and ascent aerothermodynamics research program, proximity testing of a generic bimese wing-body configuration was conducted in NASA Langley's Aerothermodynamics Laboratory in the 20-Inch Mach 6 Air Tunnel. The objective of this work is the development of experimental tools and testing methodologies to apply to hypersonic stage separation problems for future multi-stage launch vehicle systems. Aerodynamic force and moment proximity data were generated at a nominal Mach number of 6 over a small range of angles of attack. The generic bimese configuration was tested in a belly-to-belly and back-to-belly orientation at 86 relative proximity locations. Over 800 aerodynamic proximity data points were taken to serve as a database for code validation. Longitudinal aerodynamic data generated in this test program show very good agreement with viscous computational predictions. Thus a framework has been established to study separation problems in the hypersonic regime using coordinated experimental and computational tools.
\end{abstract}

\section{Nomenclature}

$\begin{array}{ll}\mathrm{B}_{\text {ref }} & =\text { lateral reference length, in } \\ \mathrm{C}_{\mathrm{A}} & =\text { axial-force coefficient (uncorrected) } \\ \mathrm{C}_{\mathrm{m}} & =\text { pitching-moment coefficient } \\ \mathrm{C}_{\mathrm{N}} & =\text { normal-force coefficient } \\ \mathrm{DX} / \text { Lref } & =\text { non-dimensional X-separation increment } \\ \mathrm{DZ} / \text { Lref } & =\text { non-dimensional Z-separation increment } \\ \mathrm{L}_{\mathrm{ref}} & =\text { longitudinal reference length, in } \\ \mathrm{M} & =\text { Mach number } \\ \mathrm{P}_{\mathrm{t}} & =\text { tunnel stagnation pressure, psi } \\ \mathrm{q}_{\infty} & =\text { free stream dynamic pressure, psia } \\ \mathrm{Re}_{\infty} / \mathrm{ft} & =\text { free stream unit Reynolds number } \\ \mathrm{S}_{\mathrm{ref}} & =\text { vehicle reference area, in }{ }^{2} \\ \mathrm{~T}_{\mathrm{t}} & =\text { tunnel stagnation temperature, }{ }^{\circ} \mathrm{F} \\ \mathrm{Xc} . \mathrm{g} . & =\text { X-location of center of gravity, in } \\ \mathrm{Yc} . \mathrm{g} . & =\text { Y-location of center of gravity, in } \\ \mathrm{Zc} . \mathrm{g} . & =\text { Z-location of center of gravity, in } \\ \square & =\text { angle of attack, deg } \\ \square & =\text { angle of sideslip, deg } \\ \square \mathrm{X} & =\text { dimensional X-separation increment } \\ \square \mathrm{Z} & =\text { dimensional Z-separation increment } \\ \square \square & =\text { dimensional } \square-\text {-separation increment } \\ \square \square & =\text { dimensional } \square-\text { separation increment }\end{array}$

\footnotetext{
* Aerospace Engineer, Aerothermodynamics Branch, Mail Stop 408A

$\dagger$ Aerospace Engineer, Aerothermodynamics Branch, Mail Stop 408A.
}

This material is declared a work of the U.S. Government and is not subject to copyright protection in the United States. Published by the American Institute of Aeronautics and Astronautics, Inc., with permission 


\section{Introduction}

NASA's Integrated Space Transportation Plan (ISTP) provided a comprehensive, long-term strategy to meet future launch vehicle and technology needs combined with reduced cost and improved safety and reliability. Given the current technology levels in the areas of propulsion, structures, and materials, the technical risk for Single-StageTo-Orbit (SSTO) remains high, and advanced Reusable Launch Vehicle (RLV) design attention has returned to Two-Stage-To-Orbit (TSTO) concepts. While the TSTO concepts being considered range greatly with respect to orbiter/booster shape, propulsion system characteristics, and resulting nominal flight trajectories, all TSTO configurations present a critical need to enhance the knowledge base in two-body separation characteristics within the sensible atmosphere to satisfy both design and abort separation scenarios. The present work is part of a larger research effort at NASA to develop the tools and methodologies suitable for system-level analysis of stage separation events in the transonic, supersonic, and hypersonic flight regimes. While this effort was initiated several years ago to satisfy specific requirements in the former Next Generation Launch Technology (NGLT) program, ${ }^{1}$ the tools and methodologies being developed are generic in nature and are applicable to a broad range of launch vehicles/architectures in NASA's new Space Exploration Initiative.

The goal for stage separation analysis tools is to accurately predict the separation trajectories for components of a given multi-vehicle system and the accompanying vehicle loads and control system requirements. Separation is a dynamic process involving a number of disciplines such as steady and unsteady aerodynamics, propulsion, mechanism kinematics, mass characteristics, and atmospheric conditions. The generation and synthesis of relevant data are generally accomplished by means of selected combinations of experimental, computational, and engineering methods of varying fidelity. Wind tunnel testing is the primary means of generating static vehicle (isolated and proximity) aerodynamic characteristics. These data are directly input into a six-degree-of-freedom trajectory simulation program, typically employing a Monte-Carlo-type simulation of the parameter space, to develop a corresponding set of separation trajectories. Inviscid and viscous computational methods are used both to confirm and/or correct wind tunnel-derived static data and to extend the relevant flow and/or geometric parameter space in order to further refine these trajectory analyses. As a final step for a specific separation scenario, computational methods are used to model the unsteady motion of the vehicles, simulating a dynamic separation process.

\section{Objectives}

Research engineers at the Langley Research Center (LaRC), with support from NASA personnel at the Marshall Space Flight Center (MSFC) and the Johnson Space Center (JSC), are developing tools and methods to address aerothermodynamic issues relevant to stage/abort separation. ${ }^{2}$ The research program described herein has the following objectives:

(1) Development and demonstration of experimental tools and testing methodologies in the hypersonic regime to provide high-fidelity experimental proximity data for multi-stage launch vehicle configurations. Experimental tool development involves proximity testing of a generic next-generation TSTO configuration in the hypersonic speed regime in the 20-Inch Mach 6 Air Tunnel in the Langley Aerothermodynamic Laboratory (LAL). Generation of exploratory static aerodynamic data on a generic bimese wing-body configuration (to be described in a subsequent section) has been completed. Specially designed separation support hardware and specifically scaled models were fabricated to accomplish this testing.

(2) Application of experimental aerodynamic proximity data for validation of computational fluid dynamic tools and development of complementary engineering-level trajectory analysis programs.

The computational tool development activity includes the merging of a 6-degree-of-freedom moving body capability in the OVERFLOW-D flow solver with the newer features of the standard OVERFLOW code, resulting in a more efficient static and dynamic, viscous multi-body simulation capability. ${ }^{3}$ Experimental data obtained in the LAL serves as a valuable means of validation for these computational tools.

Engineering tool enhancements are sought through modifications to the Aerodynamic Preliminary Analysis System (APAS) and the development of software called "SepSim" for the simulation and visualization of vehicle motions in a stage separation scenario. ${ }^{4}$ Experimental data are generally the primary input to develop and exercise these trajectory simulation tools.

\section{Previous Work}

Studies of the aerodynamics of separating bodies have been performed for decades, thus experimental and computational tools currently exist to generate and utilize this type of data. For example, research to examine store 
separation problems have yielded validated methodologies that have been successfully applied to an array of flight vehicles. ${ }^{5}$ The store separation problem differs from the current topic by the simplification that, in general, only the aerodynamic characteristics of the smaller, external store are significantly disturbed from nominal conditions. The study of the parallel separation of similar-sized lifting stages also has a well-documented legacy. Some of the earliest work was initiated by the Air Force in 1959-1960 in their reusable booster studies. ${ }^{6}$ NASA followed in the early 1960s as the nation began its quest for a reusable launch vehicle system. The reader is referred to the extensive work of Decker, et al., initiated in the early 1960s and continuing through the mid-1970s.$^{6-9}$ In this program proximity testing was conducted on both simple shapes and typical TSTO configurations at supersonic and hypersonic conditions to develop the necessary experimental tools to generate aerodynamic proximity data as well as to understand the nature of support interference effects. Data generated from these studies were then input into a six-degree-of-freedom dynamic simulation program in order to simulate resulting flight trajectories. Although the final design that emerged as the Space Shuttle in the early 1970s did not have parallel lifting stages, the methodologies developed in these early separation studies laid an important foundation for the booster separation work $^{10,11}$ that was required to develop the current multi-stage system.

In the 1980s, post Shuttle development, NASA continued to examine earth-to-orbit space transportation concepts to cover a wide range of mission requirements. System analysis studies continued to examine two-stage, fully reusable systems. ${ }^{12,13}$ Following the accidental loss of the Shuttle Challenger on ascent in 1986, a focused program employing experimental and system analysis tools was initiated to look at Shuttle Orbiter boost-phase abort scenarios, i.e. separation of the orbiter from the external tank on ascent. As mentioned previously, the 1990s saw the majority of activity in RLV development focused on single-stage-to-orbit concepts in hopes of improving safety and reliability and reducing cost. With SSTO deemed too risky with current technologies, RLV studies have again returned to multi-stage systems. With continual advances in computing power, computational fluid dynamic (CFD)

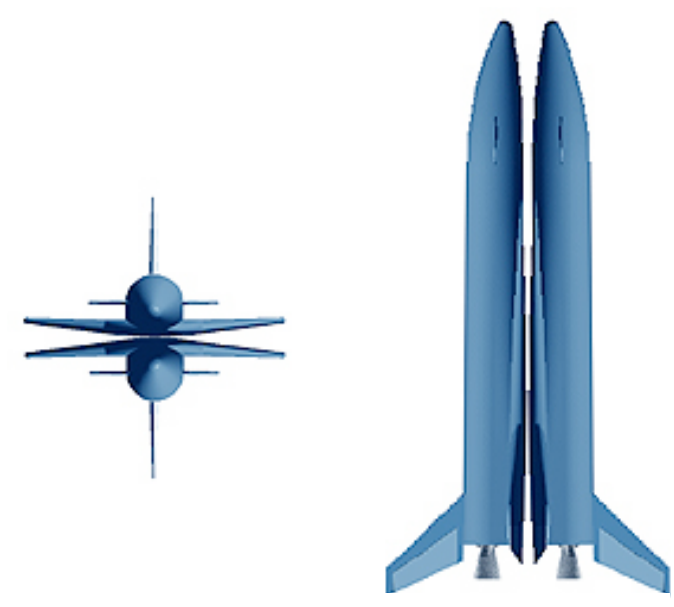

Figure 1. LGBB Bimese Arrangement

tools have now become viable to confirm and extend experimental studies in the area of separation aerodynamics. ${ }^{14}$ The stage separation tool development program, of which the work described in this paper is a part, represents a new level of coordination of both existing and new experimental, CFD, and engineering methods to develop a suite of synergistic tools to analyze aerodynamic separation issues from transonic to hypersonic conditions.

\section{Configuration Description}

In order to coordinate the tool development effort, the same generic two-stage configuration was used as the test bed for all experimental, computational, and engineering stage separation work. The Langley Glide-Back Booster (LGBB), in a belly-to-belly, bimese configuration is shown in Figure 1. The LGBB is a generic wing-body configuration that was developed by Langley Research Center's Exploration Concepts Branch for in-house multistage launch vehicle system-analysis studies. The ability to leverage off of this earlier work was the primary driver in the selection of this particular wing-body configuration.

Figure 2 shows a detailed planform schematic of the LGBB. The configuration has an 82.3-inch diameter cylindrical fuselage with a drooped, 11.2-inch-radius nose. The length from the tip of the nose to the base of the body (i.e. the engine exit plane) is 750 inches. The wing/strake is a NACA 2300 series airfoil at a 6-degree dihedral angle; the strake is swept 81.1 degrees and the wing is swept 45.3 degrees. The wing's forward swept trailing edge is a full-span elevon pair separated by a center body flap. The configuration has a center vertical tail with a leading edge sweep angle of 45 degrees. The tail's airfoil section, including a trailing edge rudder, is a NACA 0013 airfoil and its span is 110.2 inches. The baseline LGBB vehicle includes a swept canard, NACA 64A012 airfoil, located on the forward part of the fuselage; however, canards were not used in the two-stage bimese configuration. Reference dimensions for the full-scale LGBB vehicle, as well as wind tunnel models tested in the present study, are included in Table 1. 
While it is possible that there could be various sizing and arrangements of these stages, it was observed that a bimese, belly-to-belly, wing-body TSTO configuration would provide a worst case in wing-to-wing proximity effects, known to provide significant aerodynamic interference. The expectation is that if the tools can be exercised and validated for a bimese, belly-to-belly configuration, other flow fields of lesser complexity and loading will also be amenable to analysis. The

Table 1. Reference Dimensions for LGBB

\begin{tabular}{|l|l|l|}
\hline $\begin{array}{l}\text { Reference } \\
\text { Dimension }\end{array}$ & $\begin{array}{l}\text { Full-Scale } \\
\text { Flight } \\
\text { Vehicle }\end{array}$ & $\begin{array}{l}\text { 0.0121-Scale } \\
\text { (Hypersonic } \\
\text { Test Model) }\end{array}$ \\
\hline Sref & 62640 in $^{2}$ & 9.15 in $^{2}$ \\
\hline Lref & 750 in & 9.06 in \\
\hline Bref & 369 in & 4.46 in \\
\hline Xc.g. (68\%*Lref) & $\mathbf{5 1 0 ~ i n ~}$ & 6.16 in \\
\hline Yc.g. & 0 ft & 0 in \\
\hline Zc.g. & $\mathbf{0 ~ f t}$ & $\mathbf{0}$ in \\
\hline
\end{tabular}

authors recognize

that proximity effects are extremely configuration dependent, and thus any assumptions about interference $\mathrm{d}$ a $\mathrm{t}$ a $\quad \mathrm{o} \mathrm{n}$ configurations other than the one currently under study need to be examined carefully.

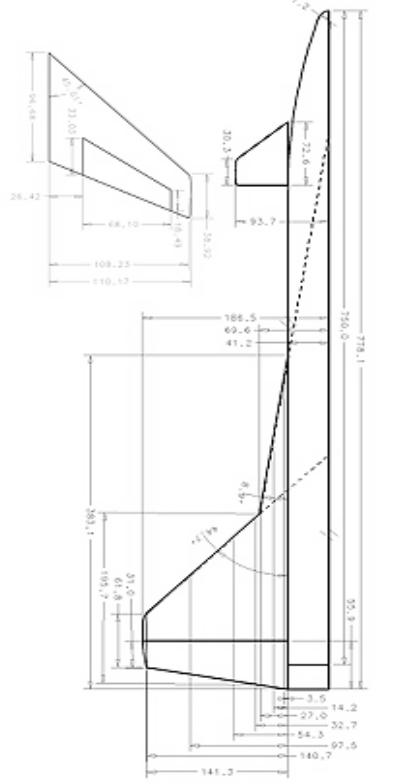

Figure 2. Planform Schematic of the LGBB Vehicle

\section{Experimental Program}

As part of program to develop experimental stage separation tools across the speed regime, proximity testing was initiated at hypersonic conditions in the LAL. The reader is referred to Reference 2 for an overview of stage separation tool development activities across the speed regime and to References 15 and 16 for a discussion of proximity testing in the supersonic regime. Clearly, two-body proximity testing is a much more complex undertaking than single-body testing. While issues such as instrumentation and model accuracy, flow modeling limitations (e.g. viscous effects), and tunnel performance (flow quality/uniformity) are just as relevant, other factors may present even greater problems for two-body systems. Aerodynamic proximity increments may be very small compared with full-scale aerodynamic loads (but nevertheless important with respect to a vehicle's stability and control characteristics in a separation maneuver) and highly non-linear and configuration dependent. Support interference and positioning accuracy are of extreme concern with the hardware required to locate one model in proximity to another. This study seeks to address the aforementioned issues in order to assess the ability to generate credible static separation data for like-scale, two-stage configurations with existing testing infrastructure in the LAL. The testing done thus far is considered exploratory in nature, with the intent of building a better understanding of testing methodologies in this facility and flow physics related to these configurations.

Facility - LaRC 20-Inch Mach 6 Air Tunnel ${ }^{17}$ : This facility, which became operational in 1958, is a blow-down wind tunnel that uses heated, dried, filtered air as the test gas. A fixed-geometry, two-dimensional contoured nozzle is used to generate Mach 6 flow in a test section with 20.5-in by 20-in cross section. Typical run times are 2-10 minutes depending on the requirements of the study and the tunnel running conditions. The tunnel can operate at stagnation pressures from 30 to 475 psi and stagnation temperatures from 750 to $1000{ }^{\circ} \mathrm{R}$, corresponding to freestream Mach numbers from 5.8 to 6.1 and unit Reynolds numbers from 0.5 to 8 million per foot. Test core size, as defined by a maximum of $\pm 1.0 \%$ variation in pitot pressure, varies from approximately $12 \times 12$ in to $14 \times 14$ in as free stream Reynolds number increases. The normal shock density ratio for this facility is 5.3 and ideal gas behavior is achieved throughout the tunnel (i.e. $\square=1.4$ everywhere). Models are mounted on an injection system located in a housing below the closed test section. A computer-operated sting support system is capable of moving the model through an angle of attack range of $-5^{\circ}$ to $+55^{\circ}$ for angles of sideslip of $\pm 8^{\circ}$. Model injection times can be as rapid as $0.5 \mathrm{sec}$. (commonly used for heat transfer tests), but generally are set for $1.2 \mathrm{sec}$. to keep model acceleration less than $2 \mathrm{~g}$ to avoid damage to the force balances.

Separation Hardware/Tunnel Modifications: As part of a program to examine Shuttle upgrade possibilities in the mid-1990s, the Liquid-Fly-Back-Booster (LFBB) program was initiated as an alternative to Shuttle replacement whereby the expendable solid rocket boosters would be replaced by fully-reusable liquid-fueled boosters that would fly-back to a designated landing site. From 1997 to 1998 the first author of this paper led the design and fabrication of a separation rig for Langley's Mach 6 tunnel and conducted the first ever multi-body separation testing in this facility in support of the LFBB program. An extensive matrix of separation data ( $\square \mathrm{X}, \square \mathrm{Y}, \square \mathrm{Z}, \square, \square)$ was generated 
to evaluate several generic LFBB concepts, but these data remain unpublished. It is the rig fabricated for the LFBB work that was used to accomplish hypersonic proximity testing for the current research effort.

The separation rig was originally designed and fabricated in-house at LaRC with subsequent modifications for LGBB testing done in-house as well. The rig, shown in Figure 9, has two main components, both machined of stainless steel. The central support mates with the tunnel strut head and is comprised of a top cylindrical-holed support (in which a sting/model can be mounted) and a rectangular column extending downward from the top support with a wedge-slab shape. This column has a series of patterned screw holes down its length such that an additional model support structure may be mounted at various Z-distances from the top model. This lower model support piece has plates that provide incremental pitch (ㄷ) and sideslip ([C) capability for the lower model. Longitudinal $\mathrm{X}$-separation is obtained via sliding the top sting to various calibrated, notched locations. This rig allows only manual adjustment of lower model position and thus only one set of separation parameters per tunnel run. As this facility is a blow-down to vacuum with limited run times, the expense and complexity of a remotedriven separation rig was not justified for this exploratory round of tests.

Model Hardware/Instrumentation: Two 1.21\%-scale (approximately 9.1-inch long) stainless steel force models were fabricated by Allied Aerospace in Newport News, VA. for separation testing in the Mach 6 facility (Fig. 3). The reference areas and lengths used to calculate aerodynamic coefficient data for these 0.0121-scale models are presented above in Table 1. The models, one tested as the "orbiter" and one tested as the "booster," are nominally identical and both designed to receive a Langley 6-component force and moment balance mounted on a straight sting support. All aerodynamic data were taken in a pitch-pause mode and corrected post-run for support system deflection under loading. Base and cavity static pressure measurements were made for both models. The matrix of model attitudes and proximity locations for tests completed in the 20-inch Mach 6 tunnel is described below.

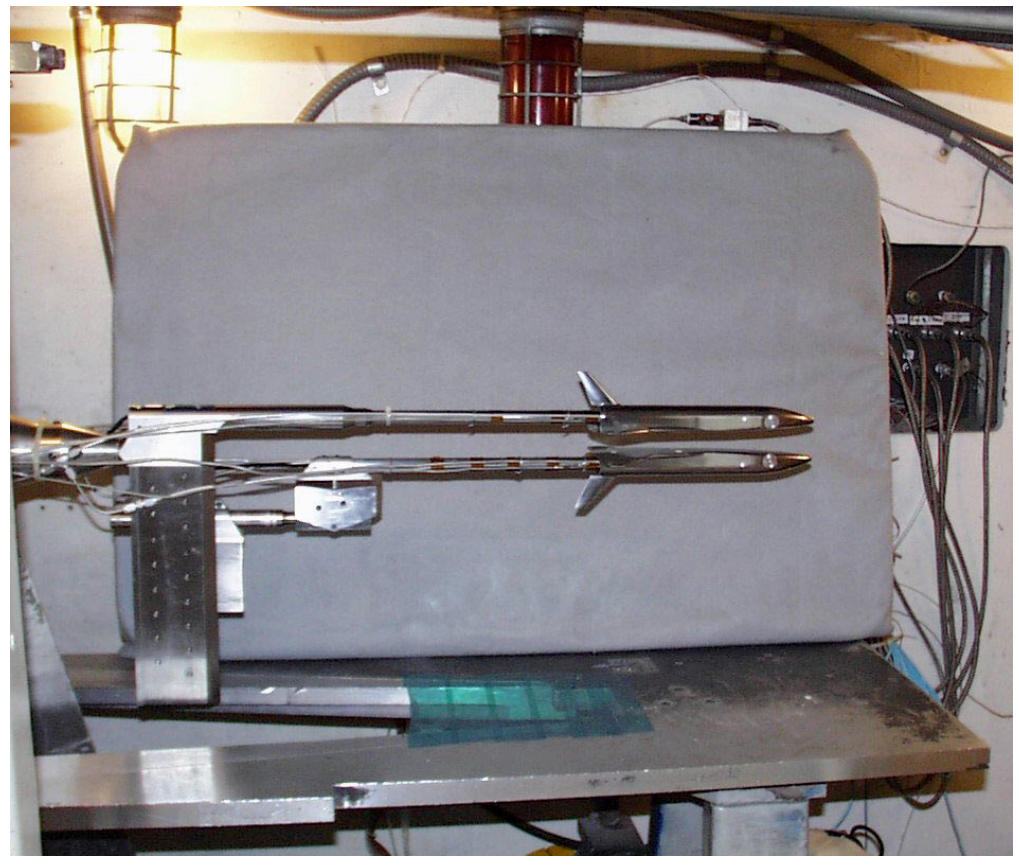

Figure 3. Separation Apparatus and Models Used for Proximity Testing at Mach 6.

Test Parameters: Figure 4 graphically shows the 86 proximity locations, derived from 11 different $\square \mathrm{X}$ locations and 8 different $\square Z$ locations, for the bimese LGBB configuration tested at Mach 6 in a belly-tobelly orientation. All $\square \mathrm{X}$ movement was achieved by moving the booster (top) model aft of the orbiter (bottom) model. All $\square \mathrm{Z}$ movement was achieved by lowering the orbiter model from the mated position. All $\square \mathrm{X}$ and $\square \mathrm{Z}$ separations were run at $\mathrm{QD}=0$ degrees and 5 degrees At each of the separation locations, both models were simultaneously swept through an angle of attack range of -4 degree to +5 degrees using the tunnel strut angle of attack mechanism. Isolated data were obtained for the orbiter and the booster with and without the presence of the lower model support structure. 


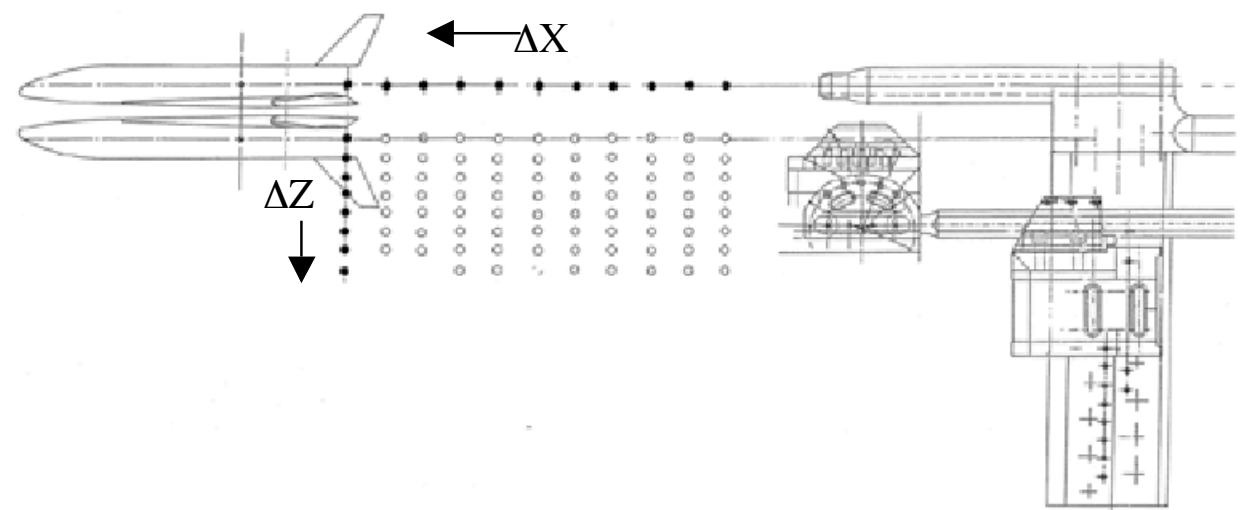

Figure 4. Detailed Schematic of LGBB proximity matrix in the 20-Inch Mach 6 Tunnel

Instrumentation and Data Uncertainty: Three aerodynamic forces and three aerodynamic moments were measured using two Langley 6-component strain gage balances. The booster model was fit to the SS02C balance and the orbiter model was fit to the SSO8B for all phases of the test program. Wind-off balance readings were monitored before and after each run, and balance components were monitored during the tunnel run for drift caused by thermal gradients across the balance gages. All aerodynamic data were taken in a pitch-pause mode and corrected post-run for support system deflection under loading. Longitudinal balance uncertainties $( \pm 95 \%$

Table 2. Balance Component Loads and Accuracies

\begin{tabular}{|c|c|c|c|c|c|c|c|}
\hline & \multicolumn{3}{|c|}{ SS02C Balance } & \multicolumn{3}{|c|}{ SS08B Balance } \\
\hline & & NF(lbs) & AF(lbs) & PM(in-lbs) & NF(lbs) & AF(lbs) & PM(in-lbs) \\
\hline \multirow{3}{*}{\multicolumn{2}{|c|}{$\begin{array}{r}\text { Maximum Load } \\
\text { Accuracy (\%full-scale) } \\
\text { Accuracy (Load) }\end{array}$}} & 100 & 10 & 60 & 100 & 20 & 60 \\
\hline & & 0.06 & 0.18 & 0.10 & 0.04 & 0.09 & 0.19 \\
\hline & & 0.06 & 0.018 & 0.06 & 0.04 & 0.018 & 0.114 \\
\hline Mach & $q \infty$ (psi) & $\begin{array}{c}\mathrm{CN} \pm 2 \square \\
\text { Accuracy }\end{array}$ & $\begin{array}{c}\mathrm{CA} \pm 2 \square \\
\text { Accuracy }\end{array}$ & $\begin{array}{c}\mathrm{CM} \pm 2 \square \\
\text { Accuracy }\end{array}$ & $\begin{array}{c}\mathrm{CN} \pm 2 \square \\
\text { Accuracy }\end{array}$ & $\begin{array}{c}\mathrm{CA} \pm 2 \square \\
\text { Accuracy }\end{array}$ & $\begin{array}{c}\mathrm{CM} \pm 2 \square \\
\text { Accuracy }\end{array}$ \\
\hline 6 & 2.7 & $\pm \mathbf{0 . 0 0 2 4}$ & \pm 0.0007 & $\pm \mathbf{0 . 0 0 0 3}$ & \pm 0.0016 & \pm 0.0007 & \pm 0.0005 \\
\hline
\end{tabular}

confidence level) for representative flow conditions are shown in Table 2. It should be noted that these balance accuracies represent only the uncertainties associated with the balance itself. This would be a measure of the overall uncertainty on the wind tunnel measurements only in the absence of all other variations. An extensive test program involving large numbers of repeat runs on all configurations at all test conditions over multiple test entries would be required to obtain rigorous uncertainty values. The data obtained thus far serve as a basis for this type of uncertainty analysis and additional focused testing and analysis will enable more detailed uncertainty calculations. Results presented herein discuss within-test repeatability for a given isolated model, as well as model-to-model repeatability.

\section{Computational Methods}

Computational Codes: In a companion computational tool development program for wing-body stage separation $^{3}$, a significant effort has been expended on merging two existing versions of the OVERFLOW NavierStokes flow solver. The resulting code is referred to as OVERFLOW 2, and includes the capabilities and features of OVERFLOW-D and OVERFLOW Version 1.8, enabling a fully-viscous, 6-degree-of-freedom, multi-body simulation capability. The Chimera overset structured grid scheme is employed, ${ }^{18}$ which is well suited for multiand moving-body applications because the grids attached to each body need only be reconnected when the bodies are moved, rather than being regenerated. The OVERFLOW-D code is the result of extensive development for a dynamic, moving-body simulation capability. ${ }^{19,20,21}$ This capability has been demonstrated on a number of applications, including store separation, rotorcraft, and missile problems. OVERFLOW-D includes 6-degree-offreedom dynamic motion, automatic background grid generation, fast hole-cutting and grid connectivity, and parallel computation via the MPI (Message Passing Interface) library. In comparison, the standard OVERFLOW 


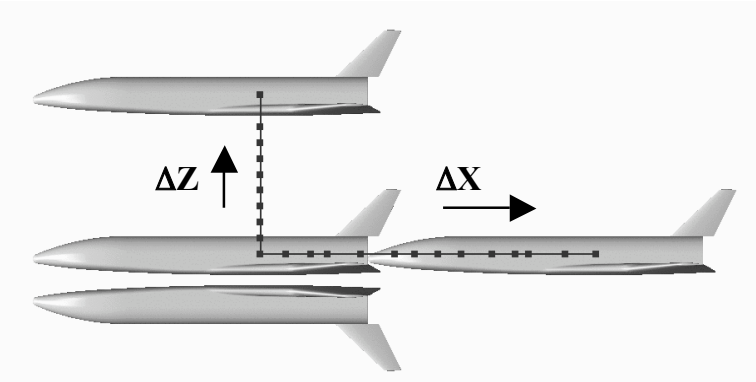

Figure 5. Orbiter and booster relative positions for sweeps in $X$ and $Z$, used in comparisons of aerodynamic forces

A matrix of cases, shown in Figure 5, was run using the OVERFLOW2 flow solver at hypersonic conditions for comparison with experimental proximity data.

\section{Results}

The test parameters detailed above have provided a large proximity database for the LGBB bimese configuration at hypersonic test conditions. With 6-component force and moment data acquired on two LGBB models for all proximity runs, the body of data generated for this test program is extremely large; thus, only a subset of the data obtained is presented herein. These results seek to assess the ability to generate credible static proximity data for like-scale, two-stage, winged configurations. This test program employed new hardware and testing methodologies, and the data presented in the sections to follow will show that repeatable, two-body proximity data can be obtained in the LAL, and that these data show very good quantitative agreement with computational proximity data.

Isolated orbiter and booster aerodynamic data are discussed first. With no sideslip or asymmetric separation conditions tested, only 3-component, longitudinal data (normal force, axial force, and pitching moment) are presented for these isolated results, as well as for all proximity results in subsequent sections. All axial force data shown is uncorrected for any base effects. Proximity results are first presented via qualitative comparisons between pitching moment proximity increments and proximity Schlieren photographs. Quantitative aerodynamic proximity results are presented for longitudinal (X) sweeps at several vertical $(\mathrm{Z})$ separations for the belly-to-belly orientation. Proximity data is primarily shown for the booster vehicle as it remains in the influence of the orbiter for a much larger region of the test space. Proximity data for the orbiter are presented only for the minimum vertical $(Z)$ separation. Proximity data for vertical $(Z)$ sweeps with no longitudinal separation are shown for both the booster and orbiter. Experimental booster and orbiter proximity data are shown compared with viscous computational data generated in a companion computational tool development program. No back-to-belly proximity data are presented.

Isolated Booster/Orbiter: To assess proximity data for a given multi-body configuration, it is first necessary to have a thorough understanding of isolated vehicle characteristics within the test envelope. Figures 6(a) - 6(c) present longitudinal aerodynamic data for the isolated booster and orbiter configurations at Mach 6. Figure 6 shows isolated values of $\mathrm{C}_{\mathrm{N}}, \mathrm{C}_{\mathrm{A}}$, and $\mathrm{C}_{\mathrm{m}}$ for the booster and orbiter models as a function of angle of attack for 16 different runs throughout the test entry (10 runs represent the isolated booster and 6 runs represent the isolated orbiter). Each plot is marked with the corresponding balance accuracies in coefficient form for reference. While the balance accuracies are a useful lower limit instrumentation resolution, the variations shown from run-to-run and model-tomodel are clearly larger and would serve as a better initial estimate of overall uncertainty. For each model at zero degrees angle of attack (where all subsequent proximity data will be presented), the run-to-run variation is on the order of the $\pm 2 \square$ balance accuracy range for $\mathrm{C}_{\mathrm{A}}$, and $\mathrm{C}_{\mathrm{m}}$, and on average a factor of three greater for $\mathrm{C}_{\mathrm{N}}$. When comparing the variations from model-to-model, these ranges approximately double. The observed variations for the coefficients $C_{N}, C_{A}$, and $C_{m}$ for this data set are approximately $\pm 0.015, \pm 0.002$, and \pm 0.001 respectively. 


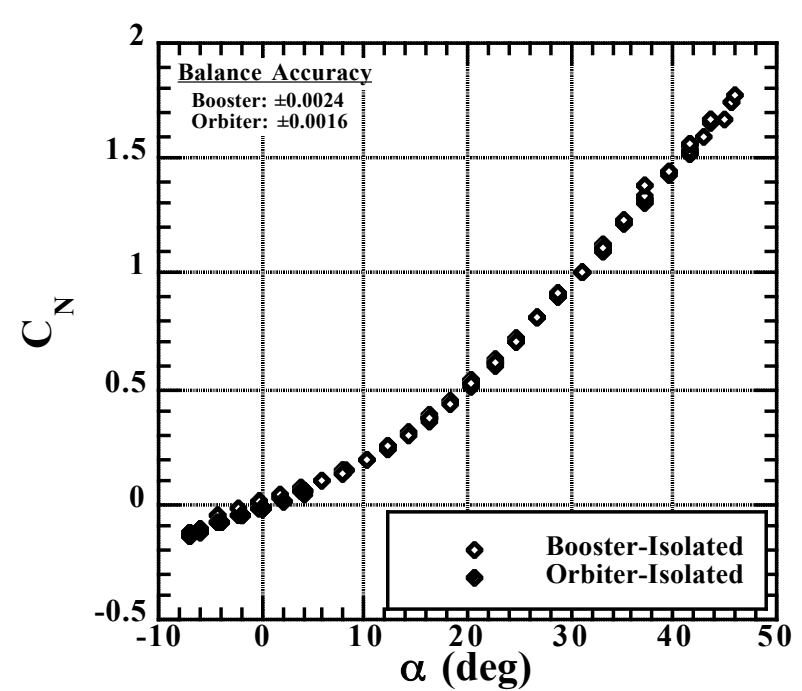

Figure 6(a). Normal Force Coefficient for Isolated LGBB Booster and Orbiter at $M=6$.

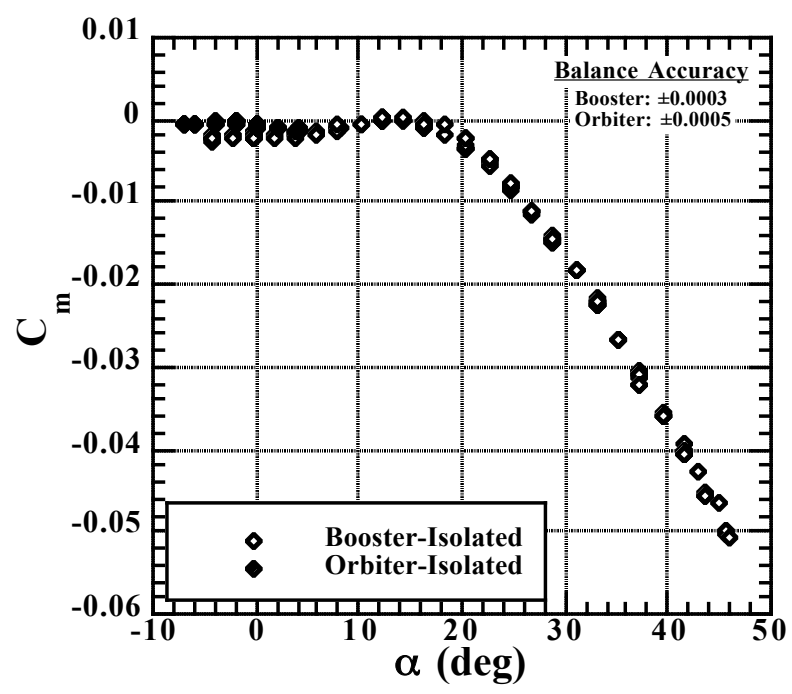

Figure 6(c). Pitching Moment Coefficient for Isolated LGBB Booster and Orbiter at $M=6$.

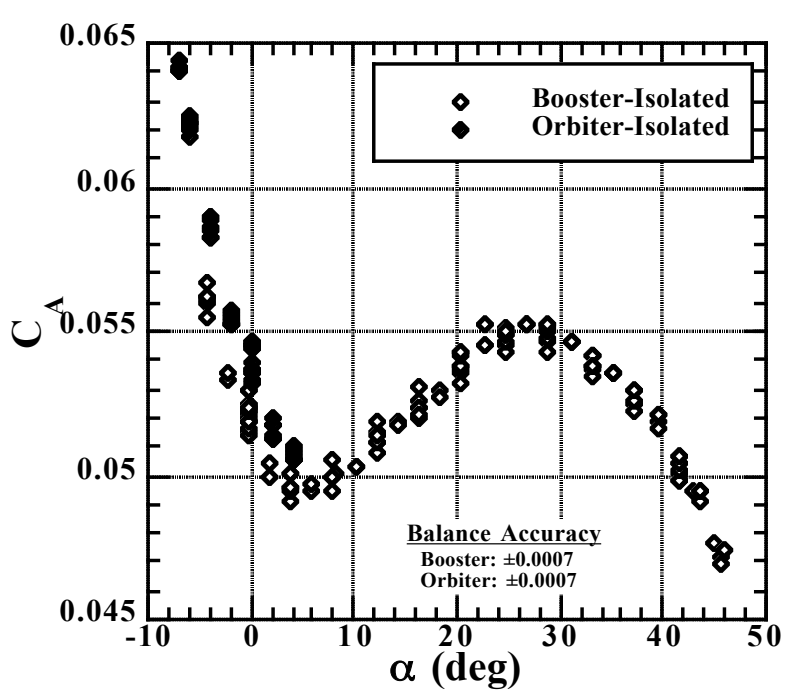

Figure 6(b). Axial Force Coefficient for Isolated LGBB Booster and Orbiter at $M=6$.

Proximity data will be presented in the sections to follow. The reader will observe some of the measured interference increments are quite small, on the order of the variations presented in the isolated data. Thus, all proximity data for the booster vehicle will be presented, where possible, with corresponding isolated data (i.e. isolated data taken at the same $\mathrm{X}$ and $\mathrm{Z}$ location as the proximity data) to provide the reader a more complete picture of the observed proximity behavior.

Qualitative Proximity Data: Due to the volume of proximity data taken in this series, a complete point-by-point and component-by-component quantitative examination of the data for both models is not feasible in a single report. A sample of the aerodynamic proximity data at Mach 6 is shown in Figure 7, where the variation of pitching moment with angle of attack for the isolated booster and the booster in proximity to the orbiter are presented. As described earlier, for each tunnel run the $\mathrm{X}$ and $\mathrm{Z}$ proximity parameters were

fixed, and then the tunnel strut (i.e. both models) was pitched through a 12 degree angle of attack excursion. For the data shown, $\mathrm{DX} / \mathrm{Lref}=0.66$ and $\mathrm{DZ} / \mathrm{Lref}=0.17$. Balance data and Schlieren photographs were recorded for seven angles of attack, with those at $\square_{\text {tunnel }}=4$ deg and $\square_{\text {tunnel }}=5$ deg shown in Fig. 7. At the two negative angles of attack, the pitching moment of the booster is more negative in the presence of the orbiter than the corresponding isolated values. The Schlieren image of this data at $\square_{\text {tunnel }}=-4$ deg shows that the orbiter bow shock strikes the booster centerline in the vicinity of the longitudinal center of gravity (c.g.). The increased pressure field between the bow shock and the wing shock (the second shock emanating from the orbiter) is entirely aft of the booster c.g. and likely contributes to the negative increment in pitching moment. As the angles of attack of both the booster and orbiter are increased, a progressive forward movement of the orbiter shock pattern on the booster is observed in the Schlieren images (only $\square_{\text {tunnel }}=5 \mathrm{deg}$ is shown). As $\square_{\text {tunnel }}$ varies from 0 to 2 degrees, the data indicate that the pressure field is balanced about the booster c.g., and the pitching moment is nearly unchanged. The change in stability over this 0 to 2 degree range cannot quantitatively be explained via Schlieren images. (More finely incremented CFD solutions at 
these conditions could provide additional insight into these interference effects.) As the orbiter shocks move forward on the booster with increasing angle of attack, the pitching moment becomes more positive.
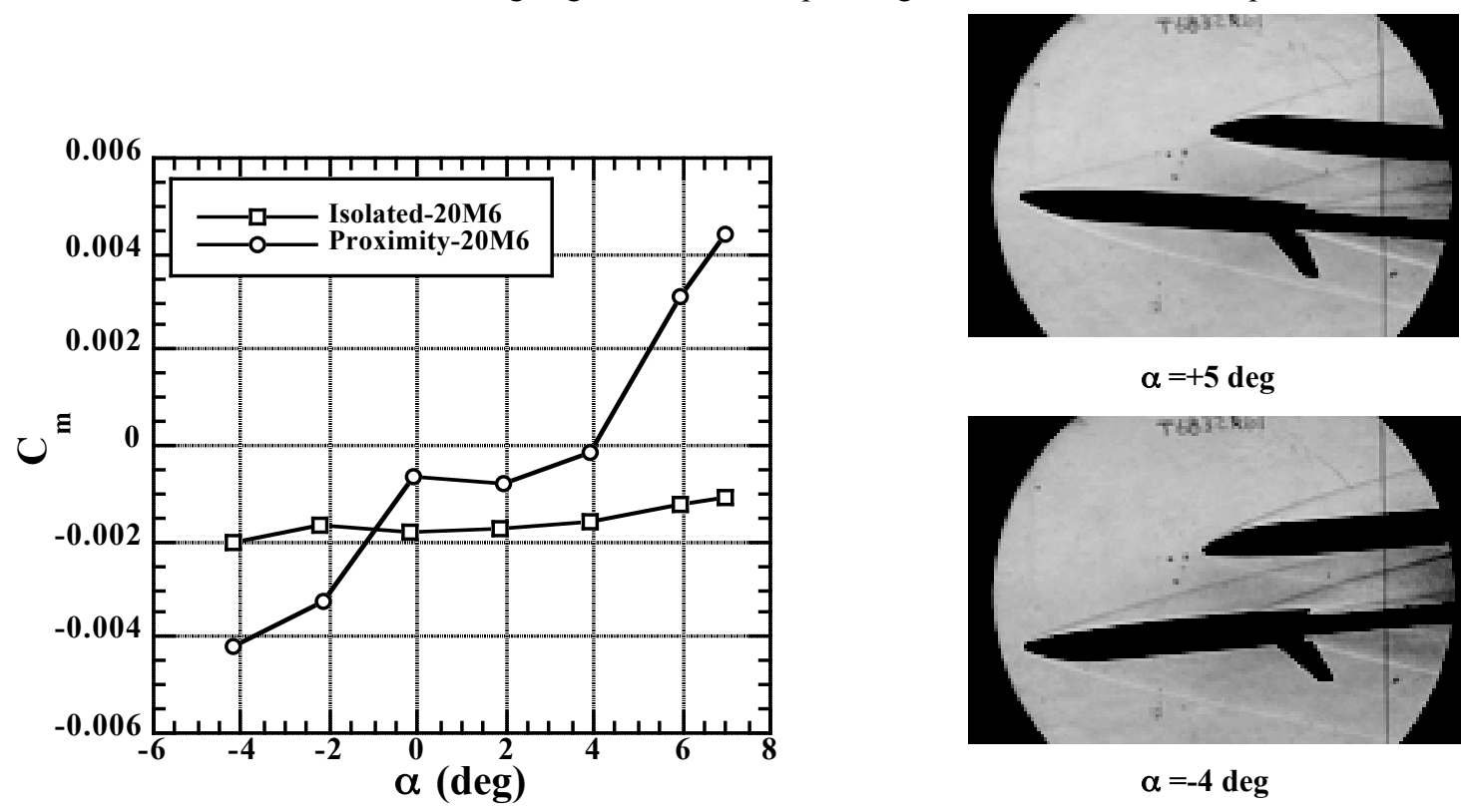

Figure 7. Pitching Moment Interference Effects at Mach 6 With Accompanying Schlieren Photographs.

Quantitative Proximity Data: Longitudinal aerodynamic characteristics, $\mathrm{C}_{\mathrm{N}}, \mathrm{C}_{\mathrm{A}}$, and $\mathrm{C}_{\mathrm{m}}$, for the LGBB booster and orbiter models in belly-to-belly proximity at $\mathrm{M}=6$ are presented in Figures 8-14. Each plot includes companion isolated data for the corresponding model. Figures 8, 9, 12, 13, and 14 present coefficient data over the range of longitudinal (streamwise) X-separation locations tested in the 20-Inch Mach 6 Tunnel (Fig. 4) for a fixed vertical (spanwise) Z-separation proximity location. Figures 10 and 11 present coefficient data over the range of vertical Zseparation locations for a fixed longitudinal X-separation location. Each data point in these plots corresponds to a different tunnel run with models at a nominal angle of attack of zero degrees. Figures 8-11 include steady, viscous computational data generated using OVERFLOW code (The reader is referred to Ref. 3 for details on the computational tool development effort)

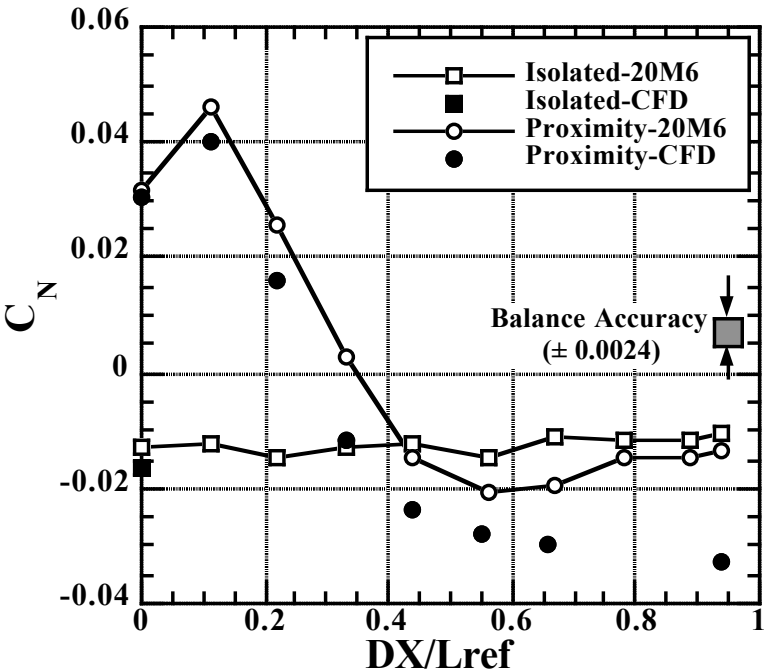

Figure 8(a). Booster Normal Force Coefficient Isolated and in Proximity, $\mathrm{DZ} / \mathrm{Lref}=\mathbf{0}, \mathrm{M}=6$.

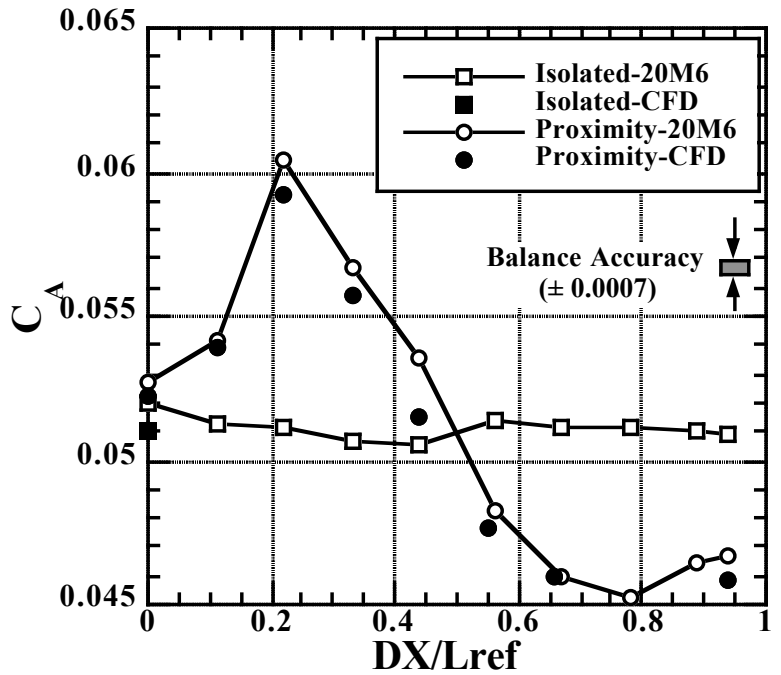

Figure 8(b). Booster Axial Force Coefficient Isolated and in Proximity, DZ/Lref $=0, M=6$. 


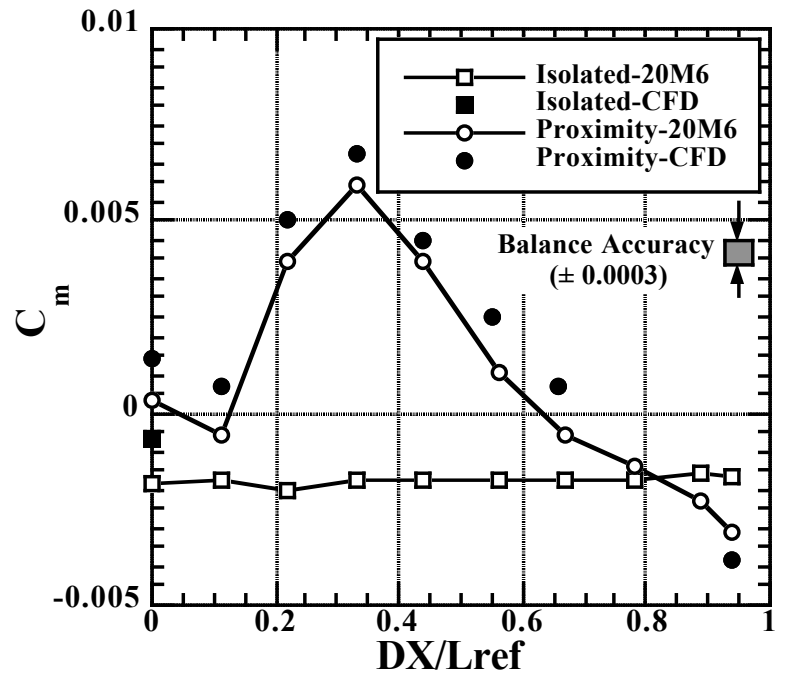

Figure 8(c). Booster Pitching Moment Coefficient Isolated and in Proximity, DZ/Lref $=0, M=6$.

Figures 8(a)-8(c) show booster aerodynamic data at the closest vertical proximity, DZ/Lref $=0$, defined as the "mated" condition, i.e. where the vehicles would be positioned relative to one another in the presence of vehicle attach hardware (no attach hardware was simulated for these tests). The minimum physical separation distance between the two 9-inch models was 0.29 in. at $\mathrm{DZ} / \mathrm{Lref}=0$. Data points in Figure 8 correspond to increasing longitudinal separation of the booster from the orbiter. Interference increments are seen to be highly non-linear for all three longitudinal components. The largest values of longitudinal interference increments occur in the first 5 inches of streamwise separation when the vehicles are in the closest overall proximity. Given the high degree of non-linearity and the coarse spacing of data points, it is recognized that maximum/minimums in the data set may not have been captured. Interference magnitudes are clearly larger than balance accuracies included in each plot. At these small separation values, the flow field region between the two models is quite complex, likely dominated by multiple shock reflections and regions of flow separation; thus, correlation of data trends with individual flow features is difficult. Pitching moment interference increments are the most significant in magnitude and trend, resulting in changes in trim and stability levels that must be accounted for by vehicle control surface capability. For all but the two most aft streamwise separation distances, the pitching moment proximity increment is positive, likely indicating that the pressure field associated with the orbiter shock system primarily impacts the booster forward of its aerodynamic center of gravity.

Comparisons between experimentally obtained data and viscous computations generated via OVERFLOW are very good for all three components, especially given the small magnitude of proximity increments. Axial force and pitching moments show excellent agreement in trend with a small offset that only slightly exceeds balance accuracy levels. Normal force deviation shows greater differences with increasing streamwise separation of the booster from the orbiter. Experimental data show a decreasing interference increment that is not predicted by computations. However, the magnitude of these differences is still within the model-to-model variations previously shown for the isolated configuration. All computation solutions were run at exactly zero degrees angle of attack while the wind tunnel model angle of attack varied as much as a \pm 0.1 deg due to sting deflections (primarily a downward deflection due to model weight). These differences in model attitude as well as expected variations in flow conditions and configuration are likely contributors to the differences between experimental measurements and computational predictions.
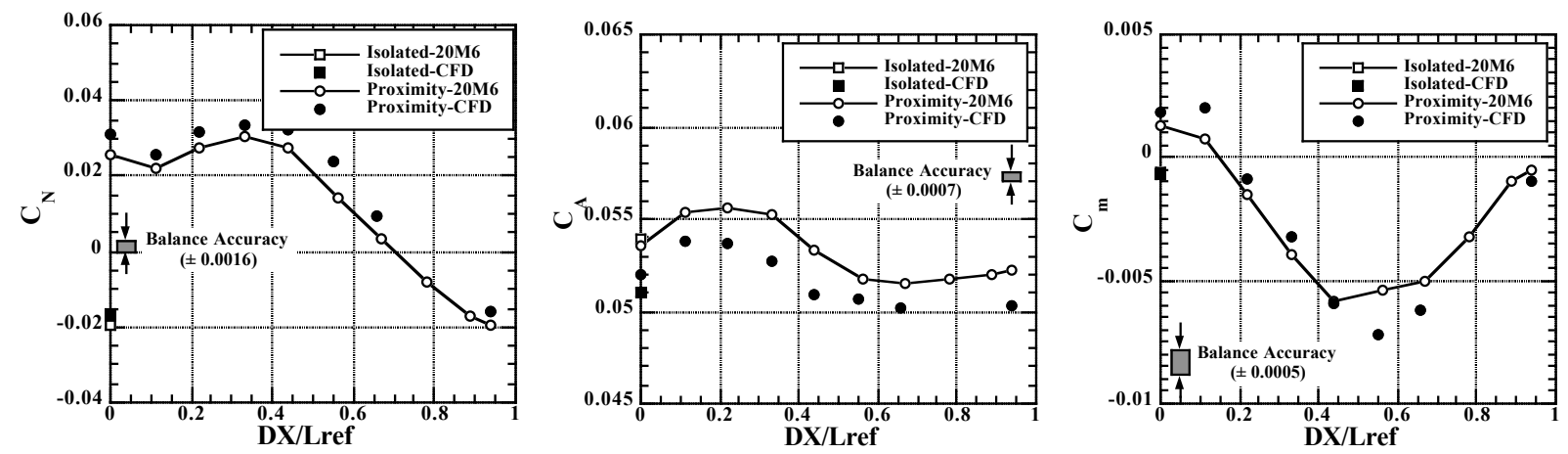

Figure 9. Orbiter Longitudinal Aerodynamic Coefficients Isolated and in Proximity, DZ/Lref=0, $M=6$.

Figure 9 shows the companion orbiter data in proximity to the booster for the same longitudinal and vertical separation parameters as in Fig. 8. Normal, Axial, and Pitching Moment coefficient data are plotted on the same 
scales for easier comparison between booster and orbiter proximity increments. Proximity increments compare well with the booster values at the mated position $(\mathrm{DX} / \mathrm{Lref}=0, \mathrm{DZ} / \mathrm{Lref}=0)$, where the proximity increments should match due to symmetry of the two-body system. Variations are expected due to physically different models (recall the isolated data in Fig. 6) as well as differences in angle of attack of as much as 0.2 degrees due to sting deflections (with the orbiter inverted, the non-zero angle of attack due to model weight will be oppositely signed to that of the booster). The overall magnitude of proximity increments is smaller for the orbiter than the booster as its flow field is less affected in the forward position. Pitching moment proximity increments are generally negative as the booster moves aft and its shock system impacts the orbiter aft of its aerodynamic center of gravity. Although it appears that coefficient values are matching the isolated values at the largest values of DX/Lref tested, longitudinal separations are not large enough to determine the boundaries of the region of influence. Comparisons with OVERFLOW aerodynamic predictions for the orbiter are similar in trend and magnitude to those previously discussed for the booster.

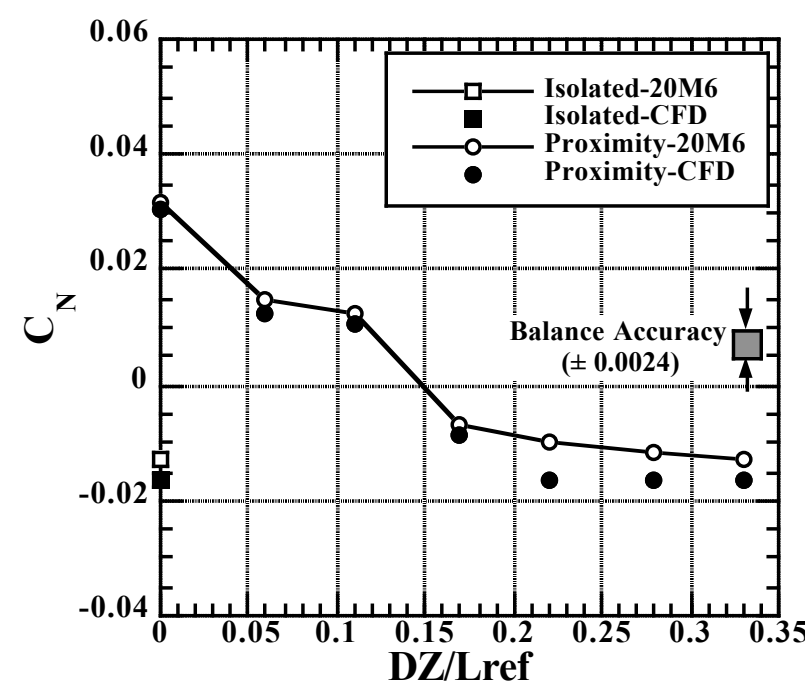

Figure 10(a). Booster Normal Force Coefficient Isolated and in Proximity, DX/Lref $=0, M=6$.

Figure 10(c). Booster Pitching Moment Coefficient Isolated and in Proximity, DX/Lref $=0, M=6$
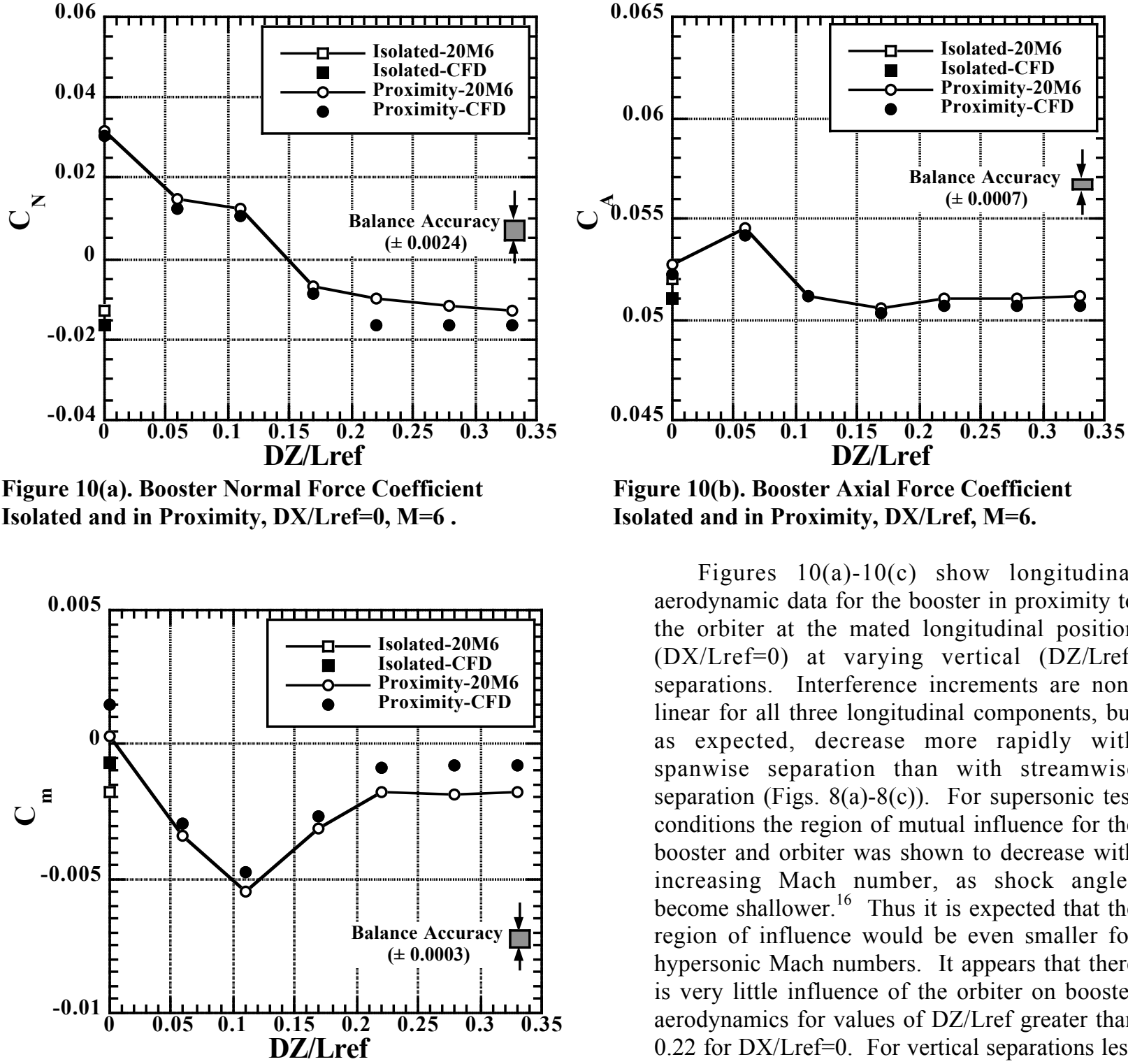

Figure 10(b). Booster Axial Force Coefficient Isolated and in Proximity, DX/Lref, $M=6$.

Figures 10(a)-10(c) show longitudinal aerodynamic data for the booster in proximity to the orbiter at the mated longitudinal position $(\mathrm{DX} / \mathrm{Lref}=0)$ at varying vertical (DZ/Lref) separations. Interference increments are nonlinear for all three longitudinal components, but as expected, decrease more rapidly with spanwise separation than with streamwise separation (Figs. 8(a)-8(c)). For supersonic test conditions the region of mutual influence for the booster and orbiter was shown to decrease with increasing Mach number, as shock angles become shallower. ${ }^{16}$ Thus it is expected that the region of influence would be even smaller for hypersonic Mach numbers. It appears that there is very little influence of the orbiter on booster aerodynamics for values of DZ/Lref greater than 0.22 for $\mathrm{DX} / \mathrm{Lref}=0$. For vertical separations less than 0.22 , interference magnitudes are seen to be larger than balance accuracies included in each plot. OVERFLOW computational predictions again show very good agreement in trend and magnitude for normal, axial, and pitching moment coefficients, with potential sources of error again attributed to model attitude, model variation, and flow conditions. Computational 
proximity data also show a return to isolated values for DZ/Lref greater than 0.22 , supporting the idea that the two bodies are no longer in a region of mutual influence. Figure 11 shows the companion orbiter proximity data corresponding to the same runs described in Fig. 10. Given the symmetry of a spanwise separation for a bimese configuration, the proximity data is expected to be the same for both the booster and the orbiter. Within the previously observed levels of variation, the orbiter proximity data set in Fig. 11 does match the booster values very closely, also indicating little or no influence of the booster for DZ/Lref values greater than 0.22 for DX/Lref $=0$.
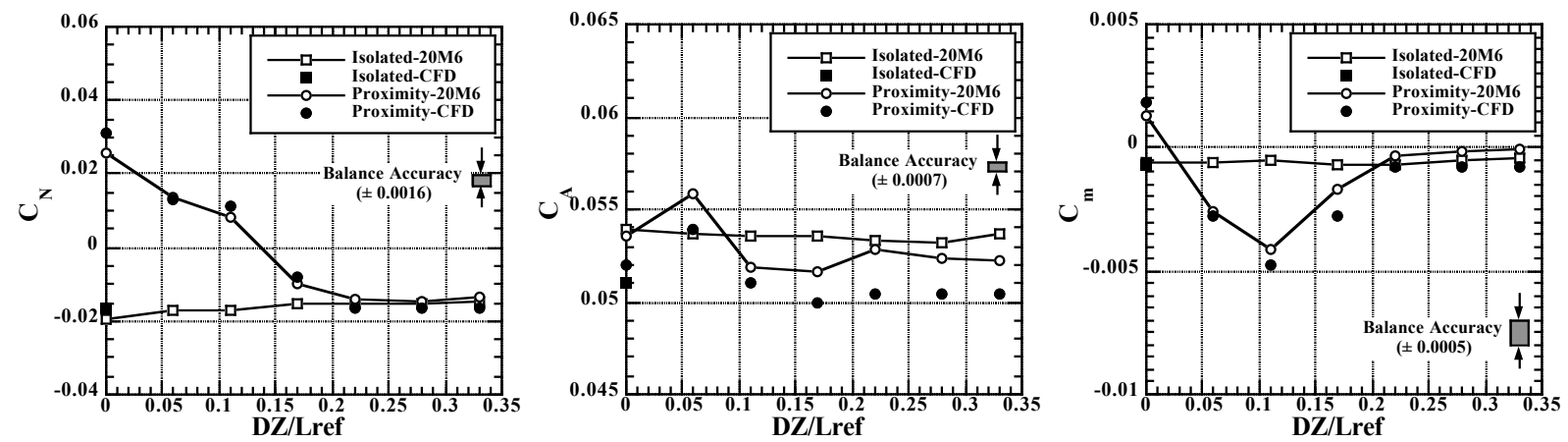

Figure 11. Orbiter Longitudinal Aerodynamic Coefficients Isolated and in Proximity, DX/Lref=0, M=6

Figures 12,13, and 14 show similar booster longitudinal-sweep interference plots to Fig. 8, but at DZ/Lref separation values of $0.11,0.22$, and 0.33 , respectively. Non-linear trends in proximity increments are observed for $\mathrm{DZ} / \mathrm{Lref}=0.11$ and $\mathrm{DZ} / \mathrm{Lref}=0.22$ for all longitudinal coefficients with the range in overall magnitude decreasing with increasing vertical separation distance. Pitching moment increments show the largest variation in sign as a function of both $\mathrm{X}$ and $\mathrm{Z}$ separation, indicative of complex shock impingements and reflections moving fore and aft
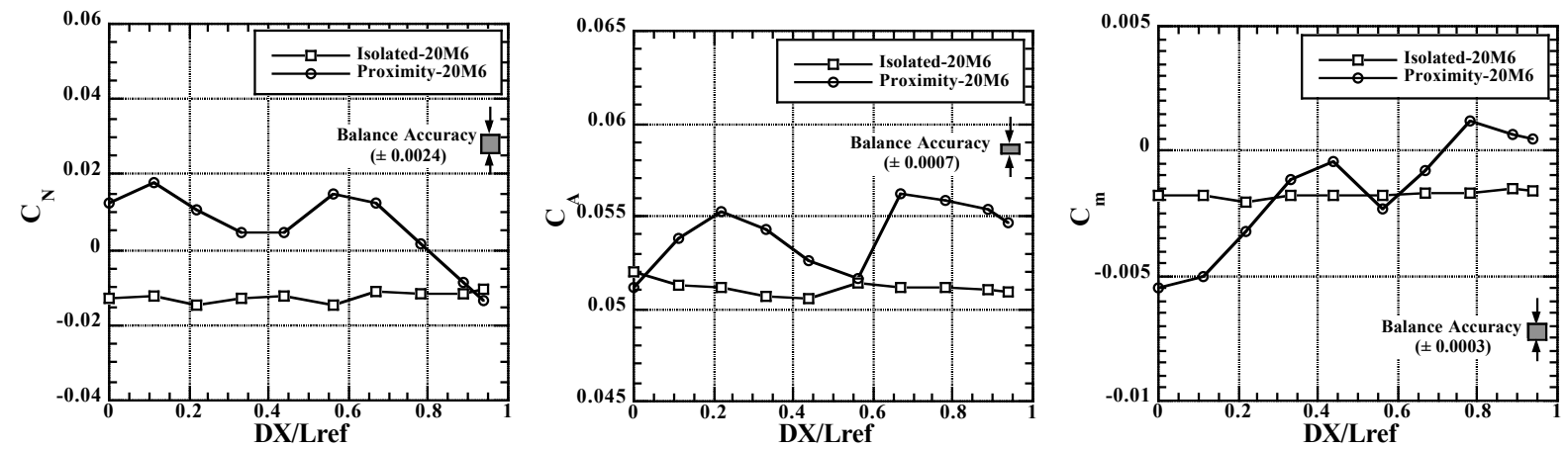

Figure 12. Booster Longitudinal Aerodynamic Coefficients Isolated and in Proximity, $D Z / L r e f=0.11, M=6$
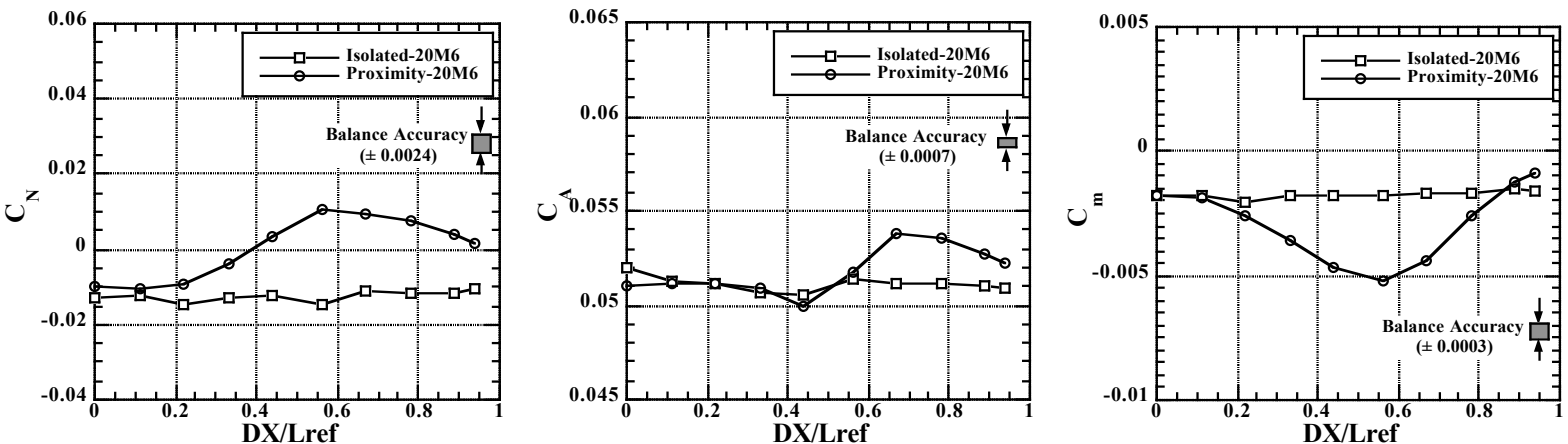

Figure 13. Booster Longitudinal Aerodynamic Coefficients Isolated and in Proximity, $D Z / L r e f=0.22, M=6$ 

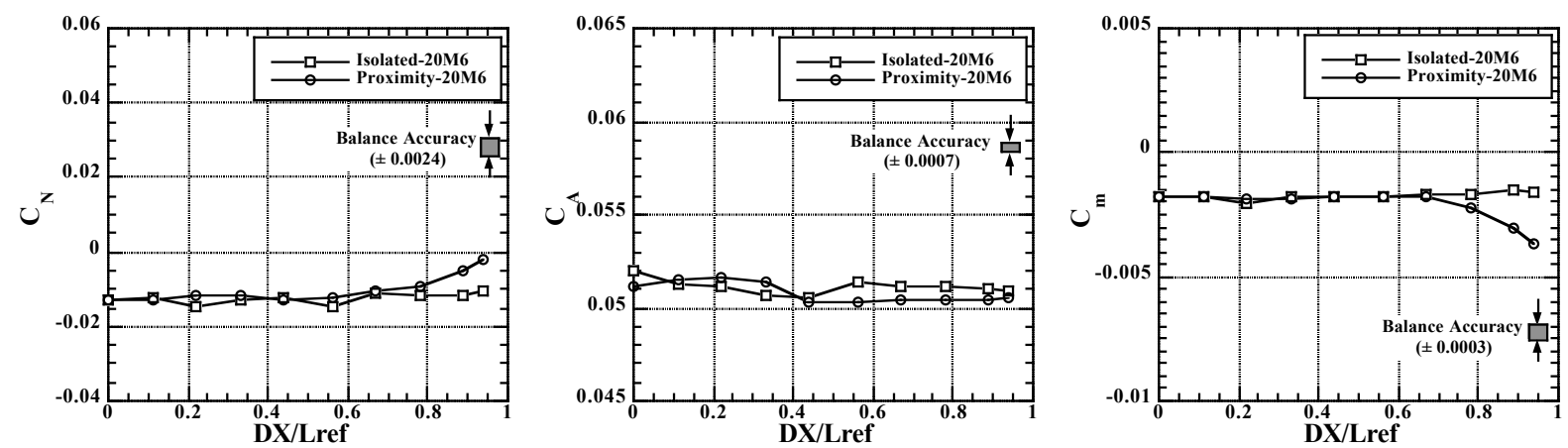

Figure 14. Booster Longitudinal Aerodynamic Coefficients Isolated and in Proximity, $D Z / L r e f=0.33, M=6$.

of the booster's center of gravity. At the furthest vertical separation, DZ/Lref $=0.33$, coefficient values return to isolated values for the majority of the data shown, and it appears that there is very little influence of the orbiter on booster aerodynamics except at the largest longitudinal separations. With the booster and orbiter at smaller values of longitudinal separation but larger value of vertical separation shock interactions likely occur well aft of the two bodies due to shallow shock angles at hypersonic conditions. As the booster moves into this aft region, interactions occur with the widening orbiter shock cone. Physical limitations of the tunnel test section and the separation rig size did not permit a thorough mapping of the influence boundary for these flow conditions.

\section{Summary and Conclusions}

Development of synergistic stage separation tools is underway at NASA in the experimental, computation, and engineering methods arenas to address issues associated with nominal and abort separations of like-scale, wing-body TSTO concepts. A common generic bimese configuration was used to exercise and compare these tools.

Exploratory experimental aerodynamic data has been acquired in the hypersonic speed regime. Hypersonic testing was accomplished in the 20-Inch Mach 6 Air Tunnel within the Langley Aerothermodynamic Laboratory by modifying a pre-existing, multi-body test apparatus. Isolated and proximity longitudinal aerodynamic data were obtained at Mach 6 for 86 relative spatial locations with the bimese, belly-to-belly Langley Glide-Back Booster configuration.

Data repeatability was examined via isolated runs for both the booster and orbiter configurations. Run-to-run repeatability was found to be approximately a factor of one to three times greater than the $\pm 2 \square$ balance measurement accuracies. When comparing the variations from model-to-model, these ranges approximately doubled.

For all separation conditions, proximity increments were shown to be larger than balance accuracy limits (i.e. measurable) and highly non-linear. Companion Schlieren imagery provided qualitative physical explanations of some trends in proximity increments. Given the high degree of non-linearity and the coarse spacing of data points, it is recognized that maximum/minimums in the data set may not have been captured. Some evidence of interferencefree data was seen at certain extreme separation positions, but physical limitations of the tunnel test section and the separation rig size precluded a thorough mapping of the influence boundary for these flow conditions.

Viscous CFD solutions generated via OVERFLOW compared very well in trend and magnitude with experimentally measured data over the range of separation parameters, thereby establishing the credibility of both tools.

\section{Acknowledgments}

The authors wish to thank the numerous technicians and engineers at the 20-Inch Mach 6 Air Tunnel at the NASA Langley Research Center. Grateful acknowledgement is extended to Pieter Buning at NASA Langley and Reynaldo Gomez of NASA Johnson Space Center for generating the OVERFLOW results shown here. 


\section{References}

1. NGLT Fact Sheet, http://www1.msfc.nasa.gov/NEWSROOM/background/facts/ngltfacts.pdf, Nov. 2003.

2. Murphy, K.J., et al., Overview of Transonic to Hypersonic Stage Separation Tool Development for MultiStage-To-Orbit Concepts, AIAA Paper 2004-2595, June 2004.

3. Buning, P. G., Gomez, R. J., CFD Approaches for Simulation of Wing-Body Stage Separation, AIAA Paper 2004-4838, August 2004.

4. Pamadi, B. N., et al., Simulation and Analyses of Staging Maneuvers of Next Generation Reusable Launch Vehicles, AIAA Paper 2004-5185, August 2004.

5. Dillenius, M.F.E., Perkins, S.C., and Nixon, D., Pylon Carriage and Separation of Stores, AIAA Progress in Astronautics and Aeronautics:Tactical Missile Aerodynamics-General Topics, M. J. Hemsch, ed., Vol. 141, 1992.

6. Decker, J. P, Aerodynamic Separation Characteristics of Conceptual Parallel-Staged Reusable Launch Vehicle at Mach 3 To 6, NASA-TM X-1051, Langley Research Center, Jan. 1965.

7. Decker, J.P, Gera, J., An Exploratory Study of Parallel-Stage Separation of Reusable Launch Vehicles, NASA-TN D-4765, Langley Research Center, Oct. 1968.

8. Decker, J.P, Aerodynamic Interference Effects Caused By Parallel-Staged Simple Aerodynamic Configurations at Mach Numbers of 3 and 6, NASA TN D-5379, Langley Research Center, Aug. 1969.

9. Decker, J.P., Wilhite, A.W., Technology and Methodology of Separating Two Similar Size Aerospace Vehicles Within the Atmosphere, L-9805, AIAA $13^{\text {th }}$ Aerospace Science Meeting, Pasedena, CA, Jan. 1975.

10. Craig, M.K., Dresser, H.S., Shuttle Booster Separation Aerodynamics, NASA Center for AeroSpace Information (CASI), pp. 139-157, 1983.

11. Wilhite, A.W., Analysis of Separation of the Space Shuttle Orbiter from a Large Transport Airplane, NASA TM X-3492, Langley Research Center, June 1977.

12. Naftel, J.C., Wilhite, Cruz, C.I., Analysis of Separation of a Two-Stage Winged Launch Vehicle, AIAA Paper 86-0195, Jan. 1986.

13. Naftel, J.C., Wilhite, A.W., Aerodynamic Separation and Glideback of a Mach 3 Staged Orbiter, AIAA Paper 90-0223, Jan. 1990.

14. Buning, P.G., et al., Compuational Fluid Dynamics Prediction of Hyper-X Stage Separation Aerodynamics, Journal of Space Craft and Rockets, Vol 38, No. 6, 2001, pp.820-827.

15. Bordelon, W.J., Frost, A.L., Reed, D.K., Stage Separation Wind Tunnel tests of a Generic Two-Stage-toOrbit Launch Vehicle, AIAA Paper 2003-4227, July 2003.

16. Murphy, K.J., Erickson, G.E., Goodliff, S..L, Experimental Stage Separation Tool Development in NASA Langley's Unitary Plan Wind Tunnel, AIAA Paper 2004-4727, August 2004.

17. Micol, J.R., Langley Aerothermodynamic Facilities Complex: Enhancements and Testing Capabilities, AIAA Paper 98-0147, Jan. 1998.

18. Steger, J.L., Dougherty, F.C., and Benek, J.A., A Chimera Grid Scheme, Advances in Grid Generation, K.N. Ghia and U. Ghia, eds., ASME FED Vol. 5, June 1983. 
19. Meakin, R.L., Object X-Rays for Cutting Holes in Composite Overset Structured Grids, AIAA Paper 20012537, June 2001.

20. Meakin, R.L., Automatic Off-Body Grid Generation for Domains of Arbitrary Size, AIAA Paper 20012536, June 2001.

21. Chan, W.M. Meakin, R.L., and Potsdam, M.A., CHSSI Software for Geometrically Complex Unsteady Aerodynamic Applications, AIAA Paper 2001-0539, Jan. 2001.

22. Buning, P.G., et al., OVERFLOW User's Manual, Version 1.8ab, NASA Langley Research Center, July 2003.

23. Jespersen, D.C., Pulliam, T.H., and Buning, P.G., Recent Enhancements to OVERFLOW, AIAA Paper 970644, Jan. 1997. 